\title{
Examining the accuracy of caregivers' assessments of young children's oral health status
}

\author{
Dr. Kimon Divaris, DDS, PhD [Research assistant professor] \\ Department of Pediatric Dentistry, School of Dentistry, The University of North Carolina at Chapel \\ Hill, 228 Brauer Hall, CB\#7450, Chapel Hill, N.C. 27599-7450, divarisk@dentistry.unc.edu
}

Dr. William F. Vann Jr., DMD, PhD [Research professor]

Department of Pediatric Dentistry, School of Dentistry, The University of North Carolina at Chapel Hill

\author{
Ms. A. Diane Baker, MBA [research associate] \\ Department of Pediatric Dentistry, School of Dentistry, The University of North Carolina at Chapel \\ Hill \\ Dr. Jessica Y. Lee, DDS, MPH, PhD [professor] \\ Department of Pediatric Dentistry, School of Dentistry, and Department of Health Policy and \\ Management, Gillings School of Global Public Health, The University of North Carolina at Chapel \\ Hill
}

\section{Abstract}

\begin{abstract}
Background-Caregivers' perceptions of their young children's oral health status (OHS) are a strong determinant of whether the children visit a dentist. Our aims were to quantify the correlation between caregivers' assessments and their children's clinically determined restorative treatment needs, while investigating factors related to this association.
\end{abstract}

\begin{abstract}
Methods-One hundred eight caregivers assessed their children's OHS by answering a question on the self-reported National Health and Nutrition Examination Survey III instrument. Children underwent clinical oral examinations at one of two study sites of the Carolina Oral Health Literacy Project: a dental school-based clinic and a community-based health clinic. Examiners recorded the children's clinical treatment needs by using a modification of the caries severity index. The authors quantified concordance between the two measures with use of the Spearman rank correlation $(\rho)$ and Kendall $\tau$ rank correlation, whereas they assessed differences in sociodemographic factors and oral health literacy (OHL) levels by using a homogeneity $\chi^{2}$ test $(P<.2$ criterion).

Results-The concordance between caregivers' assessments and clinically determined OHS was lower for younger children ( $<2$ years, $\rho=0.29$ versus $\geq 2$ years, $\rho=0.63$ [homogeneity $P=.03$ ]), a pattern that was evident in the community clinic but not in the university clinic. Caregivers' age, education and OHL did not influence the accuracy of self-reports.
\end{abstract}

Conclusions-For children younger than 2 years, caregivers' assessments correlated poorly with clinical needs, which routinely were underestimated.

Practice Implications-These findings underscore the importance of preventive dental visits at a young age and the early establishment of a dental home.

Copyright @ 2012 American Dental Association. All rights reserved

Correspondence to: Kimon Divaris.

Disclosure. The authors did not report any disclosures. 


\section{Keywords}

Children; early childhood caries; caregivers; self-reports; prevention; oral health literacy; dental home; first dental visit

The significant impact of oral disease among young children and their families is well established. ${ }^{1}$ Despite the mobilization and concerted efforts of professional and advocacy organizations, ${ }^{2-5}$ recent evidence suggests that improvements in the oral health of young children in the United States has not accompanied the decreasing trend in caries prevalence in all other age groups, ${ }^{6}$ a finding that highlights a complex problem. Conceptual models that describe the possible influences on children's oral health include a constellation of proximal and distal determinants that range from genetic and biological to cultural and social. ${ }^{7-10}$

\section{BACKGROUND}

There is a fundamental difference in approaching the prevention of oral disease in preschool-aged children versus doing so in older children. This is due, in part, to young children's total dependence on caregivers for essentially all of their oral health oversight and supervision. ${ }^{11,12}$ For children aged 0 to 36 months in particular, caregivers are responsible for high-priority and pivotal oral health behaviors such as feeding, oral hygiene and visiting a dentist. ${ }^{13,14}$ It is not surprising that characteristics of caregivers have been shown to be associated with these oral health behaviors. These characteristics include socioeconomic status, education, oral health knowledge and oral health status, ${ }^{15,16}$ all of which are likely components of pathways that explain the strong correlation between caregiver factors and their children's oral health status (OHS). This association is supported consistently in epidemiologic studies of early childhood caries (ECC). ${ }^{17,18}$

Numerous reports confirm that despite published professional association policies and recommendations that the first dental visit occur at about age 1 year, ${ }^{3,19}$ the majority of children's first dental visits occur at an older age. Dye and colleagues ${ }^{20}$ reported that onehalf of children aged 2 to 5 years in the United States had not had a dental visit. Other researchers have reported that most children's first dental visits occur secondary to dental caries and its consequences, ${ }^{21}$ when prevention is too late and costly care often is essential. Although the recommendation for the dental visit at age 1 year and the establishment of a dental home provide an opportunity for anticipatory guidance and estab lishment of desirable oral health behaviors ${ }^{2,22,23}$ before disease occurs, adherence to this professional recommendation is low, in part because of practitioners' and caregivers' attitudes. ${ }^{24-27}$ With respect to the latter, two reports indicate that caregivers' assessments of their young children's OHS remain a major determinant of their dental care-seeking behavior. ${ }^{28,29}$ Moreover, it is possible that caregivers lack the expertise to detect early signs of oral disease in very young children.

Despite published professional recommendations that the first dental visit occur at about age 1 year, the majority of children's first dental visits occur at an older age.

\section{Parents' perceptions of children's oral health}

Talekar and colleagues ${ }^{30}$ and Sohn and colleagues ${ }^{14}$ conducted studies, the results of which showed that parental assessments of their preschool-aged children's OHS were associated significantly with perceived treatment needs and actual disease, but these researchers did not quantify the actual level of agreement between the two estimates. The study by Talekar and 
colleagues $^{30}$ involved the use of National Health and Nutrition Examination Survey (NHANES) data, which did not include children younger than 2 years.

Although some variation and heterogeneity in the accuracy of caregivers' assessments likely exist, factors that may influence or modify these associations, such as the caregiver's age and education, as well as the children's age, have not been reported, to our knowledge. At the same time, researchers have linked oral health literacy (OHL) with a plethora of oral health behaviors and outcomes, so OHL is emerging as a novel construct warranting consideration in dental practice, public health and research. ${ }^{31-33}$ Recent reports also suggest that caregivers' OHL is a determinant of their children's OHS ${ }^{12}$ and may act as a modifier in the association between OHS and children's oral health-related quality of life. ${ }^{34}$ Whether caregivers' OHL may be associated with their ability to assess their children's OHS has not been reported, to our knowledge.

Therefore, we embarked on this study to add to the knowledge base pertaining to the accuracy of caregivers' reports of their children's OHS.

\section{Study aims}

We examined the accuracy of caregivers' assessments of their children's OHS by quantifying their correlation with the children's clinically determined treatment needs. We hypothesized that caregiver- and child-related factors, including caregiver's age, education and OHL and children's age, may have had an effect on caregivers' assessments of their children's OHS. Therefore, we evaluated these factors as modifiers of the aforementioned correlation.

\section{METHODS}

\section{Study sample}

We relied on data from structured interviews with 108 caregivers whose children underwent clinical oral examinations at one of two study sites: a dental school-based clinic (site $1 ; \mathrm{n}=$ 53) and a community-based nondental health clinic (site $2 ; n=55$ ). All were enrollees in the Carolina Oral Health Literacy (COHL) study, for which detailed reports of sampling, recruitment and interview procedures are published elsewhere. ${ }^{33,35}$ In short, the COHL parent study is an ongoing prospective study in which investigators examine caregivers' OHL and related outcomes among children younger than 60 months and their caregivers, who are clients of the Special Supplemental Nutrition Program for Women, Infants, and Children (WIC) in North Carolina. We should note, however, that the 108 dyads in this study were not included in previous studies, and not all participants were WIC clients. ${ }^{12,33}$

The institutional review board at the University of North Carolina at Chapel Hill approved the study, which included clinical examinations of the children at the two study sites: a community-based WIC program and a university-based dental clinic in the Department of Pediatric Dentistry, University of North Carolina. Although the university clinic is a specialty care facility, it also serves as a dental home for many healthy children who visit for regular and continuing care. We recruited healthy children from this dental clinic and from a community-based WIC clinic of which the caregivers were clients. We enrolled children 36 months and younger who were accompanied by their primary caregiver. We obtained written informed consent from all caregivers.

\section{Variable measurement}

Participating caregivers assessed their children's OHS by answering a question from the selfreported NHANES III survey instrument: "How would you assess the condition of your child's teeth and gums?" The answer options are "excellent," "very good," "good," "fair" 
and "poor." After the interview, three trained examiners whose technique was calibrated recorded the children's actual treatment needs by using a modification of Wong's adaptation of the caries severity index (CSI). ${ }^{35-37}$ Using this classification system, the examiners categorized children into one of three groups: 1 , caries-free with no treatment needs; 2 , low to moderate treatment needs, defined as visible occlusal and posterior interproximal carious lesions; and 3, advanced treatment needs, defined as visible anterior carious lesions. ${ }^{35}$

Three examiners performed the oral health examinations in the university-based clinic. After two training sessions, the interexaminer agreement coefficient (Cohen $\kappa$ ) was 0.71, indicating substantial agreement. A board-certified pediatric dentist (J.Y.L.) served as the trainer for the three examiners and conducted all examinations in the community clinic; therefore, interexaminer variability likely was not a major source of bias.

Trained research assistants conducted structured in-person interviews to collect data regarding caregivers' and children's sociodemographic characteristics and caregivers' OHL. We measured OHL by using Rapid Estimate of Adult Literacy in Dentistry-30 (REALD-30), a validated word recognition test. ${ }^{38}$ For descriptive purposes, we measured education as a four-level categorical variable: 1 , did not finish high school; 2 , high school diploma or General Educational Development (GED) credential; 3, some technical or college education; and 4 , college degree or higher. For the purpose of homogeneity testing, we coded education as a dichotomous variable wherein 1 equals high school diploma/GED credential or less, and 2 equals some technical or college education or higher. We collected additional information about the caregiver's age (measured in years) and number of children, as well as the children's race (white, African American, Latina/Latino and other), sex and age (measured in months).

\section{Analytical strategy}

We used summary statistics to describe the participating dyads' characteristics overall and stratified by study site. We used Fisher exact test and $t$ tests and corresponding $P$ values to compare the distribution of sociodemographic characteristics and OHS between the two study sites. To examine the accuracy of caregivers' reports of their children's OHS relative to their clinically determined treatment needs, we used descriptive, tabular and nonparametric methods, as well as graphic representations of the bivariate associations. Although the subjective assessments of OHS and the CSI classification are not directly comparable, evidence in the published literature supports the statistical association between the two measures. ${ }^{14,30}$

We then quantified the correlation between the NHANES III item-based assessments and the CSI classification in the entire sample of 108 dyads by using two measures of agreement: Spearman $\rho$ and Kendall $\tau$. Based on a rank-transformation approach, these nonparametric methods are used to measure the strength and monotonicity of correlation between two or more ordinal variables, ${ }^{39,40}$ a procedure analogous to obtaining an intraclass correlation coefficient. ${ }^{41}$ Spearman $\rho$, also known as the rank correlation coefficient, essentially is an application of Pearson $r$ to the rank order of observations. Kendall $\tau$ involves the use of a formula different from that used for $\rho$; it takes into account concordant and discordant pairs of observations. $\tau$-c, also called Kendall-Stuart $\tau$-c, is a statistic adjusted appropriately for large, nonsquare tables (that is, those with an unequal number of rows and columns). ${ }^{42}$ Values of $\rho$ and $\tau$ are not interpretable as the Pearson $r$ statistic, which is a measure of linear association, with $r^{2}$ corresponding to the variance explained.

Cohen $^{43}$ and Evans ${ }^{44}$ proposed empirical classifications of interpreting correlation strength by using $r{ }^{44}$ Cohen recommended that 0.10 to 0.30 be interpreted as a weak correlation, 0.30 to 0.50 as a moderate correlation and greater than 0.50 as a strong correlation. 
According to Evans' classification, less than 0.20 is very weak, 0.20 to 0.39 is weak, 0.40 to 0.59 is moderate, 0.60 to 0.79 is strong and 0.80 or greater is a very strong correlation.

Because these classifications refer to linear associations and their interpretation is specific to the subject area, one should use them with caution; nevertheless, it is commonly accepted that higher absolute values and smaller associated $P$ values imply a stronger departure from a null hypothesis of no correlation.

Caregivers systematically overestimated their children's oral health status.

To determine whether caregiver- or child-related factors influenced the level of agreement or correlation between subjective and objective assessments of OHS, we explored five factors as potential effect measure modifiers (EMMs). Examination of effect measure modification (homogeneity) refers to the determination of whether an estimated effect measure (such as treatment effect, measure of agreement) in a population under study varies substantially across the levels of another variable of interest, such as age or sex. Findings of a departure from homogeneity indicate that the effect under study is not uniform across certain subgroups of the study population. Although we could not find other studies in which investigators assessed EMM directly in this context to guide our selection of candidate modifiers, we relied on the fact that both child- and caregiver-level factors are wellestablished determinants of children's OHS. ${ }^{8,9}$ Therefore, we evaluated caregivers' and children's ages, as well as caregivers' OHL and education, as potential modifiers by using information from published research and conceptual models that documented the influence of child- and parent-level variables on pediatric OHS. ${ }^{8,45,46}$

We also examined study site as a potential modifier, as one might argue that caregivers visiting the university clinic could be higher users of the oral health care system and may have been motivated to seek care secondary to their children's oral health-related symptoms, or they may have been referred (which may have increased awareness of their child's OHS). For this analytical step, we defined the following dichotomous stratification variables:

- $\quad$ caregiver's age: young, younger than 29 years; older, 29 years or older;

- $\quad$ children's age: young, younger than 24 months; older, 24 through 39 months;

- $\quad$ OHL: low, REALD-30 score less than 13; higher, REALD-30 score 13 or higher;

- $\quad$ education: low, high school diploma/GED credential or less; high, some technical or college education or more;

- $\quad$ study site: 1 , university-based clinic;

2, community-based clinic.

Our rationale for choosing these cutoffs was based on specific characteristics of the sample (the median age of caregivers was 29 years), previous research (investigators have used REALD-30 scores $<13$ to define low $\mathrm{OHL}^{12,34}$ ) and interpretational purposes (that is, the motivation to examine this question among children younger than 2 years).

We assessed heterogeneity (EMM) by performing empirical contrasts of the correlation coefficients (Spearman $\rho$ and Kendall $\tau$ ) between the examined strata, as well as by conducting formal $\chi^{2}$ tests of homogeneity or of a common estimate. ${ }^{47}$ Because our evaluation of homogeneity was based on de facto underpowered tests, we set a conservative $P$ value criterion of .20 to determine departure from homogeneity. After applying a Šidák correction $^{48}$ for five post hoc tests, we set the resulting critical $P$ value threshold to .04 . We performed all analyses by using statistical software (Stata 12.1, StataCorp, College Station, Texas). 


\section{RESULTS}

Table 1 presents the descriptive information for the 108 caregiver-child dyads. ${ }^{33,38}$ The study sample consisted primarily of female caregivers. Most children in the university clinic were white, whereas most children in the community clinic where African American. Caregivers and children at the community clinic were on average 3 years and 3 months younger, respectively, than those at the university clinic. The mean REALD-30 score for caregivers at the community clinic was 1.5 points lower than that for caregivers at the university clinic. The CSI classifications for the entire sample were as follows: no treatment needs, 52 percent; low to moderate needs, 19 percent; and advanced needs, 30 percent. We found some differences between sites with respect to the CSI classification (no treatment needs, 53 percent in community clinic versus 51 percent in university clinic; advanced treatment needs, 17 percent in community clinic versus 42 percent in university clinic).

Table 2 presents the estimates of concordance stratified by variables of interest. ${ }^{38}$ Although the OHS and CSI assessments were associated sta tistically $(P<.005)$, their overall correlation was moderate $(\rho=0.44 ; 95$ percent confidence limits $=0.26,0.62 ; \tau-c=0.39)$. Evidently, children's age and study site modified this association, with the correlation being significantly smaller (homogeneity $P<.04)$ among younger $(<2$ years) children $(\rho=0.29)$ and dyads at the community clinic $(\rho=0.13)$. Although our sample size did not permit further stratification, we found that the modifying effect of children's age persisted when we limited the analysis to dyads at the community clinic but not to those at the university clinic.

The figure presents a graphic representation of this association according to study site; an evident gradient is observed for the university clinic dyads versus a less-defined pattern of association for the community clinic dyads. Specifically, in the university-based clinic, caregivers' assessments of "excellent" and "very good" corresponded to no clinical treatment needs, "good" corresponded to a midpoint between no and mild/moderate needs, and virtually all "fair" and "poor" assessments corresponded to advanced treatment needs. In the community-based clinic, however, caregivers' assessments ranging from "excellent" to "fair" showed virtually no correlation with, or variation by, clinical treatment needs; only reports of "poor oral health status" were associated with advanced treatment needs.

In Table 3 (page 1244), we present the cross tabulation of the caregiver-reported OHS versus the CSI classification, overall and stratified by the two variables that emerged as important modifiers: children's age and study site. ${ }^{33,35-37}$ The vast majority ( $\approx 93$ percent) of children who were found to be healthy in the clinical examination were reported by their caregivers to have excellent, very good or good OHS; this proportion did not vary according to children's age or study site. Conversely, for one-third of the children with advanced treatment needs, their caregivers reported that they had excellent, very good or good OHS. We should note that all five dyads in which children had advanced treatment needs and their caregivers reported OHS as excellent or very good included children younger than 2 years who were seen at the community clinic.

\section{DISCUSSION}

\section{Caregiver-reported OHS}

In this study of 108 caregiver-child dyads, we found that caregivers' assessments of their children's OHS and their clinically determined restorative treatment needs were statistically associated; however, the correlation was moderate. Caregivers systematically overestimated their children's OHS, and this discordance was more pronounced for children younger than 2 years and for those who visited the community clinic rather than the university clinic. This is 
an important finding because caregivers' assessments are important motivators of dental care-seeking and children's oral health behaviors. $25,29,49,50$

The findings of this study are in agreement with published reports in which researchers compared caregiver-reported OHS and clinically determined OHS among young children and found a statistically significant association between the two. ${ }^{14,30}$ However, our findings include quantitative estimates of this correlation; we also report on factors that may modify it and provide insight into the direction of discordances. Our investigation included an oral examination, an important added component with respect to previous studies in the field of OHL research. ${ }^{12}$ Our data add to the knowledge base by providing agreement estimates of the association between self-reports and clinical status. Specifically, we found that the correlation was of moderate magnitude, and the observed discordance was virtually unidirectional; caregivers overestimated their young children's OHS or, inversely, underestimated their treatment needs.

\section{First dental visit}

One implication of our findings is that caregivers may not be equal to the responsibility of determining their young children's need for dental care. Instead, they require guidance and counseling with regard to embracing optimal oral health behaviors, including timely initiation of preventive dental visits. ${ }^{51}$ The value of, and rationale for, an early preventive visit, commensurate with the eruption of the first primary tooth at about age 1 year, are based on the principle of timely diagnosis and anticipatory guidance. ${ }^{3,11}$ In addition to identifying frank or incipient disease at an early age, the visit at age 1 year provides an opportunity for clinicians to educate caregivers about and sensitize them to the value of their children's oral health, while offering key messages about optimal oral health behaviors. In particular, this visit allows for the early recognition of deleterious oral health behaviors that can be eliminated or modified before they lead to disease.

The value of the dental visit at age 1 year is enhanced by early preventive efforts via a caries risk assessment ${ }^{1,2,52,53}$ and the availability and efficacy of fluoride varnish application. ${ }^{54,55}$ Early evaluation of an infant's or a young child's oral health and caries risk factors in the context of the family, social and cultural environment can offer additional insights into the constellation of factors that may contribute to ECC. ${ }^{56}$ Moreover, Savage and colleagues 57 reported that early preventive dental visits increase the rate of subsequent preventive dental visits and substantially reduce future dental health-related costs.

From a clinical and dental public health perspective, our finding of poor accuracy of parental assessments of their young children's OHS is of concern. According to a recent populationbased household survey conducted by Baldani and colleagues, ${ }^{29} 50.5$ percent of children from birth to 6 years of age in a Brazilian state had never had a dental visit. In that study, better perceived OHS, no reported oral health problems and no perceived treatment needs were associated with a significantly higher proportion of children who never had had a dental visit. The findings of U.S. studies corroborate the finding that caregivers' knowledge, perceptions and attitudes toward oral health may lead to suboptimal and deleterious dental care-seeking patterns for children. ${ }^{45,58,59}$ The results of a community-based study by Horton and Barker ${ }^{58}$ revealed that caregivers of children younger than 6 years did not always recognize visible signs of ECC and did not respond quickly unless the children complained of pain.

Between 1988 and 1994 and 1999 and 2004, children in the 2-to 4-year-old age group were the only people in the United States to exhibit an increase in caries prevalence. ${ }^{20}$ In an environment characterized by rapid demographic changes and growing oral health inequalities, ${ }^{60}$ caries prevention in this vulnerable age group appears more challenging than 
ever. The American Academy of Pediatrics (AAP) Section on Pediatric Dentistry and Oral Health used data from the Medical Expenditure Panel Survey to estimate that only 1.5 percent of infants and 1-year-old children had had a dental visit in 2000-2005, compared with almost 90 percent who had had a visit to a pediatrician. ${ }^{19}$ This statistic is indicative of the poor adherence to the recommendation for a dental visit at age 1 year, but it illustrates the potential role of pediatricians in screening patients and referring those with oral health problems, as well as in delivering preventive dental care services (such as application of fluoride varnish). ${ }^{19,61,62}$ In anticipation of updated national statistics, and in light of the fact that caregiver-perceived treatment needs are a poor motivator for preventive care and anticipatory guidance, we strongly support efforts to disseminate the recommendation for the dental visit at age 1 year, as endorsed by the American Academy of Pediatric Dentistry ${ }^{3}$ and AAP. ${ }^{19}$

\section{Community clinic versus university clinic}

The age-modification effect was evident in the entire sample and in the community clinic group, but not in the university clinic group. This observation warrants further investigation, but a preliminary explanation may be that because participants from the university clinic were seeking dental care at the time of the survey, they may have had different characteristics from those of participants from the community clinic. For example, it is possible that these families were seeking care secondary to a referral by their pediatrician or family practitioner.

Our nonrejection of the assumption of homogeneity for caregiver-related variables such as age, education and OHL does not imply that these factors are not associated with the accuracy of caregivers' reports. Rather, our results suggest that these factors likely are weak candidate modifiers compared with children's age, study site or care-seeking status. One must consider these findings in view of the study's limitations. This study was based on a small to moderate sample of 108 caregiver-child dyads in two study sites, which did not permit the use of parametric methods and multivariate analyses to adjust for confounders. Except for the exploratory stratification by study site, the reliance on nonparametric methods did not permit the simultaneous stratification by multiple caregiver- and child-related factors in our heterogeneity analyses. A larger sample size that might allow further stratification on important sociodemographic and clinical environmental characteristics may provide additional insight into the research question.

In our study, the university clinic sample was composed of care-seeking caregiver-child dyads, which could be associated with an elevated awareness of OHS, prior information in the case of referral, or known restorative treatment needs. Although we did not collect such information, we cannot exclude the possibility that children's painful symptoms or difficulty feeding led parents to seek care at the university clinic, and thus it is possible that these parents may have perceived a worse OHS for their child compared with caregivers visiting the community clinic. In addition, we performed a juxtaposition of two distinct indexes: a global measure of caregiver-reported children's OHS and a clinically determined treatment needs index. Although direct comparisons should be made with caution, we believe that the two measures' inherent ordinality and covariance, as well as their conceptual linkage to a common construct (children's oral disease), allowed for valid inferences on the basis of these analytical iterations.

A major strength of this study is its exploration of an important question regarding the accuracy of caregiver-reported OHS. This is a critical area of inquiry because the vast majority of dental public health, surveillance and outcomes research is based on selfreported data. Our results also add to the knowledge base because we included a large proportion of children younger than 2 years, and we provided information about potential 
caregiver- and child-level modifiers pertaining to the accuracy of caregiver reports of children's OHS. We cannot overemphasize the importance of effective strategies to promote caregiver education ${ }^{63-65}$ regarding children's oral health issues, professional guidelines and best oral health practices.

\section{CONCLUSIONS}

Our study findings show that caregivers routinely overestimated their children's OHS, and agreement between their assessments and the clinically determined OHS was substantially worse for younger children. For children younger than 2 years, caregivers' assessments correlated poorly with actual clinical treatment needs, which caregivers routinely underestimated. These findings underscore the importance of early preventive visits and the early establishment of a dental home, as well as provide support for the recommendation of the first dental visit's occurring when the child is aged 1 year. Major improvements in pediatric oral health likely will be realized only when effective and efficient strategies to educate caregivers are implemented.

\section{Acknowledgments}

The Carolina Oral Health Literacy study was supported by grant RO1DE018045 from the National Institute of Dental and Craniofacial Research, National Institutes of Health, Bethesda, Md.

\section{ABBREVIATION KEY}

$\begin{array}{ll}\text { AAP } & \text { American Academy of Pediatrics } \\ \text { COHL } & \text { Carolina Oral Health Literacy } \\ \text { CSI } & \text { Caries severity index } \\ \text { ECC } & \text { Early childhood caries } \\ \text { EMM } & \text { Effect measure modifiers } \\ \text { GED } & \text { General Educational Development } \\ \text { NHANES } & \text { National Health and Nutrition Examination Survey } \\ \text { OHL } & \text { Oral health literacy } \\ \text { OHS } & \text { Oral health status } \\ \text { REALD-30 } & \text { Rapid Estimate of Adult Literacy in Dentistry-30 } \\ \text { WIC } & \text { Women, Infants, and Children }\end{array}$

\section{References}

1. Casamassimo PS, Thikkurissy S, Edelstein BL, Maiorini E. Beyond the dmft: the human and economic cost of early childhood caries. JADA. 2009; 140(6):650-657. [PubMed: 19491160]

2. Edelstein B. Policy issues in early childhood caries. Community Dent Oral Epidemiol. 1998; 26(1 suppl):96-103. [PubMed: 9671206]

3. American Academy of Pediatric Dentistry; American Academy of Pediatrics. Policy on early childhood caries (ECC): classifications, consequences, and preventive strategies. Pediatr Dent. 2008; 30(7 suppl):40-43. [PubMed: 19216381]

4. Edelstein BL. Solving the problem of early childhood caries: a challenge for us all. Arch Pediatr Adolesc Med. 2009; 163(7):667-668. [PubMed: 19581553]

5. O'Keefe J. Editorial. Collective efforts to combat early childhood caries. J Can Dent Assoc. 2009; 75(8):557. [PubMed: 19847960] 
6. Tomar SL, Reeves AF. Changes in the oral health of US children and adolescents and dental public health infrastructure since the release of the Healthy People 2010 Objectives. Acad Pediatr. 2009; 9(6):388-395. [PubMed: 19945073]

7. Patrick DL, Lee RS, Nucci M, Grembowski D, Jolles CZ, Milgrom P. Reducing oral health disparities: a focus on social and cultural determinants. BMC Oral Health. 2006; 6(suppl 1):S4. [PubMed: 16934121]

8. Fisher-Owens SA, Gansky SA, Platt LJ, et al. Influences on children's oral health: a conceptual model. Pediatrics. 2007; 120(3):e510-e520. [PubMed: 17766495]

9. Mouradian WE, Huebner CE, Ramos-Gomez F, Slavkin HC. Beyond access: the role of family and community in children's oral health. J Dent Educ. 2007; 71(5):619-631. [PubMed: 17493971]

10. Mattheus DJ. Vulnerability related to oral health in early childhood: a concept analysis (published online ahead of print July 2, 2010). J Adv Nurs. 2010; 66(9):2116-2125. doi:10.1111/j.1365-2648. 2010.05372.x. [PubMed: 20626483]

11. Edelstein BL. Evidence-based dental care for children and the age 1 dental visit. Pediatr Ann. 1998; 27(9):569-574. [PubMed: 9778708]

12. Vann WF Jr, Lee JY, Baker D, Divaris K. Oral health literacy among female caregivers: impact on oral health outcomes in early childhood (published online ahead of print Oct. 5, 2010). J Dent Res. 2010; 89(12):1395-1400. doi:10.1177/0022034510379601. [PubMed: 20924067]

13. Vargas CM, Ronzio CR. Relationship between children's dental needs and dental care utilization: United States, 1988-1994. Am J Public Health. 2002; 92(11):1816-1821. [PubMed: 12406814]

14. Sohn W, Taichman LS, Ismail AI, Reisine S. Caregiver's perception of child's oral health status among low-income African Americans. Pediatr Dent. 2008; 30(6):480-487. [PubMed: 19186773]

15. Huebner CE, Riedy CA. Behavioral determinants of brushing young children's teeth: implications for anticipatory guidance. Pediatr Dent. 2010; 32(1):48-55. [PubMed: 20298653]

16. Li Y, zhang Y, Yang R, Zhang Q, Zou J, Kang D. Associations of social and behavioural factors with early childhood caries in Xiamen city in China (published online ahead of print Dec. 2, 2010). Int J Paediatr Dent. 2011; 21(2):103-111. doi:10.1111/j.1365-263X. 2010.01093.x. [PubMed: 21121987]

17. Ismail AI, Lim S, Sohn W, Willem JM. Determinants of early childhood caries in low-income African American young children. Pediatr Dent. 2008; 30(4):289-296. [PubMed: 18767507]

18. Weintraub JA, Prakash P, Shain SG, Laccabue M, Gansky SA. Mothers' caries increases odds of children's caries (published online ahead of print May 26, 2010). J Dent Res. 2010; 89(9):954958. doi: 10.1177/0022034510372891. [PubMed: 20505046]

19. American Academy of Pediatrics. Section on Pediatric Dentistry and Oral Health. Preventive oral health intervention for pediatricians (published online ahead of print Nov. 17, 2008). Pediatrics. 2008; 122(6):1387-1394. doi:10.1542/peds.2008-2577. [PubMed: 19015205]

20. Dye BA, Tan S, Smith V, et al. Trends in oral health status: United States, 1988-1994 and 19992004. Vital Health Stat. 2007; 11(248):1-92.

21. Mileva SP, Kondeva VK. Age at and reasons for the first dental visit. Folia Med (Plovdiv). 2010; 52(4):56-61. [PubMed: 21462893]

22. Nowak AJ. Rationale for the timing of the first oral evaluation. Pediatr Dent. 1997; 19(1):8-11. [PubMed: 9048406]

23. Monroy PG. The age-1 dental visit and the dental home; a model for early childhood caries prevention. J Mich Dent Assoc. 2007; 89(1):32, 34-36. [PubMed: 17393891]

24. Wolfe JD, Weber-Gasparoni K, Kanellis MJ, Qian F. Survey of Iowa general dentists regarding the age 1 dental visit. Pediatr Dent. 2006; 28(4):325-331. [PubMed: 16903440]

25. Santos CL, Douglass JM. Practices and opinions of pediatric and general dentists in Connecticut regarding the age 1 dental visit and dental care for children younger than 3 years old. Pediatr Dent. 2008; 30(4):348-351. [PubMed: 18767516]

26. Stijacic T, Schroth RJ, Lawrence HP. Are Manitoba dentists aware of the recommendation for a first visit to the dentist by age 1 year? J Can Dent Assoc. 2008; 74(10):903. [PubMed: 19126358]

27. Salama F, Kebriaei A. Oral care for infants: a survey of Nebraska general dentists. Gen Dent. 2010; 58(3):182-187. [PubMed: 20478797] 
28. Al Agili DE, Bronstein JM, Greene-McIntyre M. Access and utilization of dental services by Alabama Medicaid-enrolled children: a parent perspective. Pediatr Dent. 2005; 27(5):414-421. [PubMed: 16435643]

29. Baldani MH, Mendes YB, Lawder JA, de Lara AP, Rodrigues MM, Antunes JL. Inequalities in dental services utilization among Brazilian low-income children: the role of individual determinants. J Public Health Dent. 2011; 71(1):46-53. [PubMed: 21667543]

30. Talekar BS, Rozier RG, Slade GD, Ennett ST. Parental perceptions of their preschool-aged children's oral health. JADA. 2005; 136(3):364-372. [PubMed: 15819352]

31. Jones M, Lee JY, Rozier RG. Oral health literacy among adult patients seeking dental care. JADA. 2007; 138(9):1199-1208. [PubMed: 17785385]

32. Horowitz AM, Kleinman DV. Oral health literacy: the new imperative to better oral health. Dent Clin North Am. 2008; 52(2):333-344. [PubMed: 18329447]

33. Lee JY, Divaris K, Baker AD, Rozier RG, Lee SY, Vann WF Jr. Oral health literacy levels among a low-income WIC population. J Public Health Dent. 2011; 71(2):152-160. [PubMed: 21774139]

34. Divaris K, Lee JY, Baker AD, Vann WF Jr. Caregivers' oral health literacy and their young children's oral health-related quality of life (published online ahead of print Dec. 8, 2011). Acta Odont Scand. 2012; 70(5):390-397. doi:10.3109/00016357.2011.629627. [PubMed: 22150574]

35. Miller E, Lee JY, DeWalt DA, Vann WF Jr. Impact of caregiver literacy on children's oral health outcomes (published online ahead of print June 14, 2010). Pediatrics. 2010; 126(1):107-114. doi: 10.1542/peds.2009-2887. [PubMed: 20547644]

36. Poulsen S, Horowitz HS. An evaluation of a hierarchical method of describing the pattern of dental caries attack. Community Dent Oral Epidemiol. 1974; 2(1):7-11. [PubMed: 4153274]

37. Wong MC, Schwarz E, Lo EC. Patterns of dental caries severity in Chinese kindergarten children. Community Dent Oral Epidemiol. 1997; 25(5):343-347. [PubMed: 9355769]

38. Lee JY, Rozier RG, Lee SY, Bender D, Ruiz RE. Development of a word recognition instrument to test health literacy in dentistry: the REALD-30 - a brief communication. J Public Health Dent. 2007; 67(2):94-98. [PubMed: 17557680]

39. Conover WJ, Iman RL. Rank transformations as a bridge between parametric and nonparametric statistics. Am Stat. 1981; 35(3):124-129.

40. Raveh A. On measures of monotone association. Am Stat. 1986; 40(2):117-123.

41. Bartko JJ. The intraclass correlation coefficient as a measure of reliability. Psychol Rep. 1966; 19(1):3-11. [PubMed: 5942109]

42. Gibbons, JD. Inferences based on Rho and Tau. In: Gibbons, JD., editor. Nonparametric Measures of Association. Sage; Newbury Park, Calif.: 1993. p. 16-26.

43. Cohen, LH. Measurement of life events. In: Cohen, LH., editor. Life Events and Psychological Functioning: Theoretical and Methodological Issues. Sage; Newbury Park, Calif.: 1988. p. 11-30.

44. Evans, JD. Straightforward Statistics for the Behavioral Sciences. Brooks/Cole Publishing; Pacific Grove, Calif.: 1996.

45. Cortés DE, Réategui-Sharpe L, Spiro A III, García RI. Factors affecting children's oral health: perceptions among Latino parents (published online ahead of print Oct. 10, 2011). J Public Health Dent. 2012; 72(1):82-89. doi:10.1111/j.1752-7325.2011.00287.x. [PubMed: 22316378]

46. Okada M, Kawamura M, Kaihara Y, et al. Influence of parents' oral health behaviour on oral health status of their school children: an exploratory study employing a causal modelling technique. Int $\mathbf{J}$ Paediatr Dent. 2002; 12(2):101-108. [PubMed: 11966888]

47. Greenland, S.; Rothman, KJ. Introduction to stratified analysis. In: Rothman, KJ.; Greenland, S.; Lash, TL., editors. Modern Epidemiology. Lippincott, Williams \& Wilkins; Philadelphia: 2008. p. 258-282.

48. Abdi, H. Bonferroni and Sidak corrections for multiple comparisons. In: Salkind, NJ., editor. Encyclopedia of Measurement and Statistics. Sage; Thousand Oaks, Calif.: 2007. p. 103-107.

49. Isong IA, Zuckerman KE, Rao SR, Kuhlthau KA, Winickoff JP, Perrin JM. Association between parents' and children's use of oral health services (published online ahead of print Feb. 1, 2010). Pediatrics. 2010; 125(3):502-508. doi:10.1542/peds.2009-1417. [PubMed: 20123775] 
50. Schneider HS. Parental education leads to preventive dental treatment for patients under the age of four. ASDC J Dent Child. 1993; 60(1):33-37. [PubMed: 8432944]

51. Isong IA, Luff D, Perrin JM, Winickoff JP, Ng MW. Parental perspectives of early childhood caries (published online ahead of print Sept. 7, 2011). Clin Pediatr (Phila). 2012; 51(1):77-85. doi: 10.1177/0009922811417856. [PubMed: 21903623]

52. American Academy on Pediatric Dentistry; American Academy of Pediatrics. [Accessed Jan. 24, 2012] Guideline on caries risk assessment and management for infants, children, and adolescents. www.aapd.org/media/Policies_Guidelines/G_CariesRiskAssessment.pdf.

53. Ramos-Gomez FJ, Crall J, Gansky SA, Slayton RL, Feather-stone JD. Caries risk assessment appropriate for the age 1 visit (infants and toddlers). J Calif Dent Assoc. 2007; 35(10):687-702. [PubMed: 18044377]

54. Miller EK, Vann WF Jr. The use of fluoride varnish in children: a critical review with treatment recommendations. J Clin Pediatr Dent. 2008; 32(4):259-264. [PubMed: 18767454]

55. Weintraub JA, Ramos-Gomez F, Jue B, et al. Fluoride varnish efficacy in preventing early childhood caries. J Dent Res. 2006; 85(2):172-176. [PubMed: 16434737]

56. Kim Seow W. Environmental, maternal, and child factors which contribute to early childhood caries: a unifying conceptual model (published online ahead of print Oct. 4, 2011). Int J Paediatr Dent. 2012; 22(3):157-168. doi:10.1111/j.1365-263X.2011.01186.x. [PubMed: 21972925]

57. Savage MF, Lee JY, Kotch JB, Vann WF Jr. Early preventive dental visits: effects on subsequent utilization and costs. Pediatrics. 2004; 114(4):e418-e423. [PubMed: 15466066]

58. Horton S, Barker JC. Rural Mexican immigrant parents' interpretation of children's dental symptoms and decisions to seek treatment. Community Dent Health. 2009; 26(4):216-221. [PubMed: 20088219]

59. Barker JC, Horton SB. An ethnographic study of Latino pre-school children's oral health in rural California: intersections among family, community, provider and regulatory sectors. BMC Oral Health. 2008; 8:8. [PubMed: 18377660]

60. Cheng NF, Han PZ, Gansky SA. Methods and software for estimating health disparities: the case of children's oral health (published online ahead of print Sept. 8, 2008). Am J Epidemiol. 2008; 168(8):906-914. doi:10.1093/aje/kwn207. [PubMed: 18779387]

61. Lewis CW, Boulter S, Keels MA, et al. Oral health and pediatricians: results of a national survey. Acad Pediatr. 2009; 9(6):457-461. [PubMed: 19945080]

62. Pierce KM, Rozier RG, Vann WF Jr. Accuracy of pediatric primary care providers' screening and referral for early childhood caries. Pediatrics. 2002; 109(5):E82. [PubMed: 11986488]

63. Ismail AI. Prevention of early childhood caries. Community Dent Oral Epidemiol. 1998; 26(1 suppl):49-61. [PubMed: 9671200]

64. Rozier RG, Sutton BK, Bawden JW, Haupt K, Slade GD, King RS. Prevention of early childhood caries in North Carolina medical practices: implications for research and practice. J Dent Educ. 2003; 67(8):876-885. [PubMed: 12959161]

65. Kelly SE, Binkley CJ, Neace WP, Gale BS. Barriers to care-seeking for children's oral health among low-income caregivers. Am J Public Health. 2005; 95(8):1345-1351. [PubMed: 16043666] 


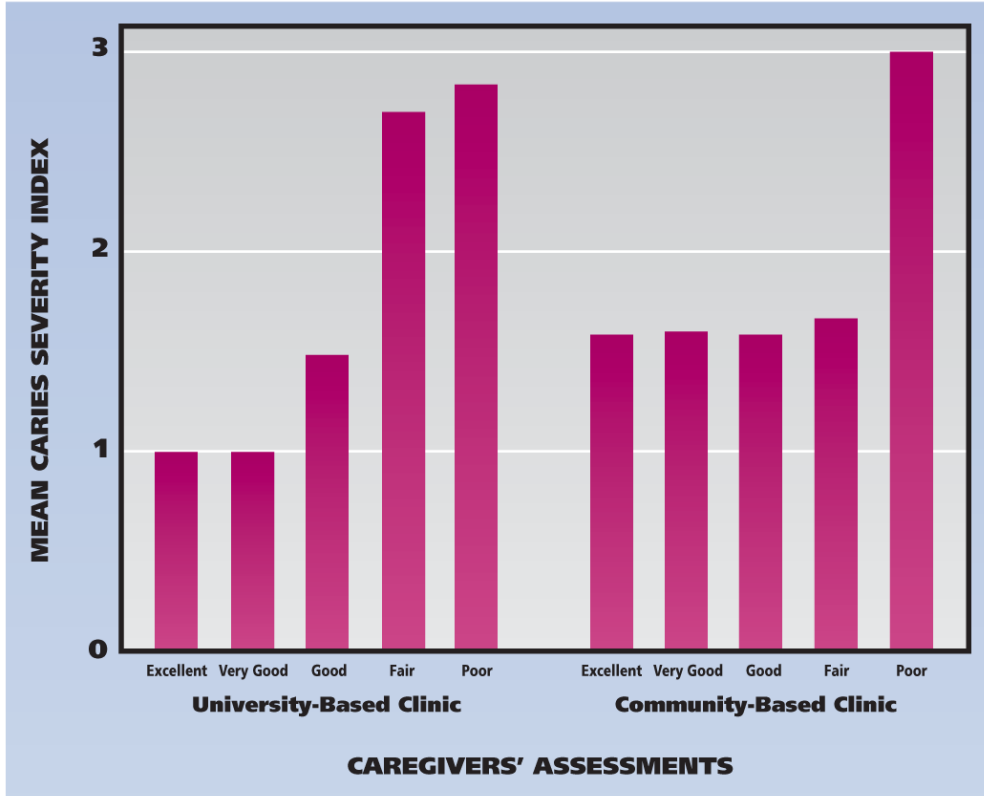

Figure.

Association between caregivers' assessments of their children's oral health status (measured with the National Health and Nutrition Examination Survey III self-reported item as excellent, very good, good, fair or poor) and their clinically determined treatment needs (measured with a modification of the caries severity index, ${ }^{35-37}$ where $1=$ no treatment needs, $2=$ low to moderate treatment needs and $3=$ advanced treatment needs) among the 108 caregiver-child dyads participating in the Carolina Oral Health Literacy ${ }^{33}$ study. 
TABLE 1

Characteristics of caregivers and children comprising 108 dyads in the Carolina Oral Health Literacy study. *

\begin{tabular}{|c|c|c|c|c|c|c|c|}
\hline \multirow[t]{2}{*}{ CHARACTERISTIC } & \multicolumn{2}{|c|}{ TOTAL SAMPLE $^{\dagger}$} & \multicolumn{2}{|c|}{ UNIVERSITY CLINIC $^{\dagger}$} & \multicolumn{2}{|c|}{ COMMUNITY CLINIC $^{\dagger}$} & \multirow{2}{*}{$\begin{array}{c}P \text { VALUE } \\
\text { (FISHER } \\
\text { EXACT OR } \\
t \text { TEST) }\end{array}$} \\
\hline & $\begin{array}{c}\text { No. of } \\
\underset{108}{\text { Participants }}\end{array}$ & $\%^{*}$ & $\begin{array}{l}\quad \begin{array}{l}\text { No. of } \\
\text { Participants } \\
=55)\end{array} \\
\quad(\mathbf{n}\end{array}$ & $\%$ & $\begin{array}{l}\text { No. of } \\
\text { Participants (n } \\
=\text { =53) }\end{array}$ & $\%$ & \\
\hline \multicolumn{8}{|l|}{ Caregivers } \\
\hline \multicolumn{8}{|l|}{ Education } \\
\hline $\begin{array}{l}\text { Did not finish high } \\
\text { school }\end{array}$ & 18 & 17 & 6 & 11 & 12 & 23 & \\
\hline $\begin{array}{l}\text { High school diploma/ } \\
\text { GED }^{\S} \text { credential }\end{array}$ & 24 & 22 & 8 & 15 & 16 & 30 & .01 \\
\hline $\begin{array}{l}\text { Some technical or } \\
\text { college }\end{array}$ & 38 & 36 & 20 & 37 & 18 & 34 & \\
\hline College degree or higher & 27 & 25 & 20 & 37 & 7 & 13 & \\
\hline \multicolumn{8}{|l|}{ Number of children } \\
\hline 1 & 35 & 33 & 21 & 38 & 14 & 27 & \\
\hline 2 & 40 & 38 & 19 & 35 & 21 & 41 & 6 \\
\hline 3 & 19 & 18 & 10 & 18 & 9 & 18 & .0 \\
\hline 4 or more & 12 & 11 & 5 & 9 & 7 & 14 & \\
\hline \multicolumn{8}{|l|}{ Relationship to the child } \\
\hline Mother & 95 & 89 & 49 & 91 & 46 & 87 & \\
\hline Father & 10 & 9 & 5 & 9 & 5 & 9 & .6 \\
\hline Grandparent & 2 & 2 & 0 & 0 & 2 & 4 & \\
\hline Age, years & $30.3(8.0)^{I /}$ & $18-63^{\#}$ & $31.9(6.9)^{\text {II }}$ & $18-47^{\#}$ & $28.7(8.6)^{I /}$ & $19-63^{\#}$ & .04 \\
\hline $\begin{array}{l}\text { Oral Health Literacy } \\
\text { (REALD-30** } \\
\text { score) }\end{array}$ & $19.8(6.5)^{\mathscr{I}}$ & $1-30^{\#}$ & $20.5(5.6)^{\mathscr{I}}$ & $4-30^{\#}$ & $19.0(7.3)^{\mathscr{I I}}$ & $1-29^{\#}$ & .2 \\
\hline \multicolumn{8}{|l|}{ Children } \\
\hline \multicolumn{8}{|l|}{ Sex } \\
\hline Male & 66 & 61 & 38 & 69 & 28 & 53 & \\
\hline Female & 42 & 39 & 17 & 31 & 25 & 47 & .1 \\
\hline Age, months & $21(7)^{I L}$ & $7-34^{\#}$ & $23(6)^{\text {Il }}$ & $7-31^{\#}$ & $20(7)^{q I}$ & $9-34^{\#}$ & \\
\hline \multicolumn{8}{|l|}{ Age, years } \\
\hline$\geq 2$ years & 47 & 44 & 31 & 56 & 16 & 30 & .01 \\
\hline$<2$ years & 61 & 56 & 24 & 44 & 37 & 70 & \\
\hline \multicolumn{8}{|l|}{ Race } \\
\hline White & 38 & 35 & 30 & 55 & 8 & 15 & \\
\hline African American & 43 & 40 & 8 & 15 & 35 & 66 & $<.005$ \\
\hline Other & 27 & 25 & 17 & 31 & 10 & 19 & \\
\hline \multicolumn{8}{|l|}{$\begin{array}{l}\text { Caregiver-reported } \\
\text { child's oral health status }\end{array}$} \\
\hline Excellent & 27 & 27 & 6 & 13 & 21 & 40 & $<.005$ \\
\hline
\end{tabular}




\begin{tabular}{|c|c|c|c|c|c|c|c|}
\hline \multirow[t]{2}{*}{ CHARACTERISTIC } & \multicolumn{2}{|c|}{ TOTAL SAMPLE ${ }^{\dagger}$} & \multicolumn{2}{|c|}{ UNIVERSITY CLINIC $^{\dagger}$} & \multicolumn{2}{|c|}{ COMMUNITY CLINIC $^{\dagger}$} & \multirow{2}{*}{$\begin{array}{c}P \text { VALUE } \\
\text { (FISHER } \\
\text { EXACT OR } \\
t \text { TEST) }\end{array}$} \\
\hline & $\begin{array}{c}\text { No. of } \\
\underset{\text { Participants }}{\text { 108 }^{t}}(\mathrm{~N}=\end{array}$ & $\%^{*}$ & $\begin{array}{l}\text { No. of } \\
\text { Participants (n } \\
=55)\end{array}$ & $\%$ & $\begin{array}{l}\text { No. of } \\
\text { Participants (n } \\
=53)\end{array}$ & $\%$ & \\
\hline Very good & 21 & 21 & 6 & 13 & 15 & 28 & \\
\hline Good & 29 & 29 & 17 & 35 & 12 & 23 & \\
\hline Fair & 16 & 16 & 13 & 27 & 3 & 6 & \\
\hline Poor & 8 & 8 & 6 & 12 & 2 & 4 & \\
\hline \multicolumn{8}{|l|}{$\begin{array}{l}\text { Clinically assessed } \\
\text { treatment needs }\end{array}$} \\
\hline None & 56 & 52 & 28 & 51 & 28 & 53 & \\
\hline Low/moderate & 20 & 19 & 4 & 7 & 16 & 30 & .001 \\
\hline Advanced & 32 & 30 & 23 & 42 & 9 & 17 & \\
\hline
\end{tabular}

Source: Lee and colleagues. ${ }^{38}$

* Source: Lee and colleagues. 33

${ }^{\dagger}$ Numbers may not total 108 because of missing information in some strata.

tUnless otherwise specified.

$\xi_{\text {GED: General Educational Development. }}$

II Mean (standard deviation).

\# Range.

***

REALD-30: Rapid Estimate of Adult Literacy in Dentistry-30. 


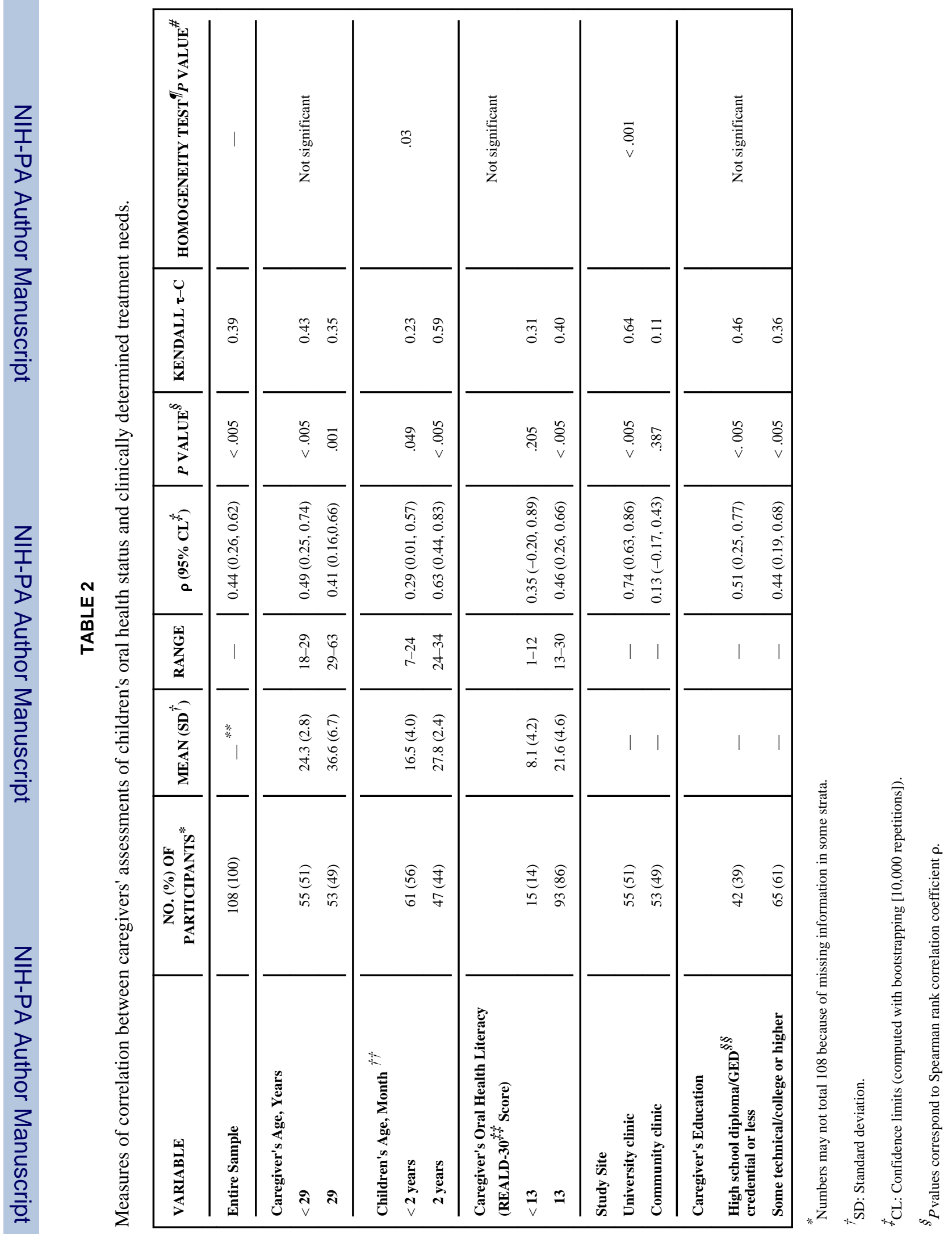

J Am Dent Assoc. Author manuscript; available in PMC 2013 November 01. 


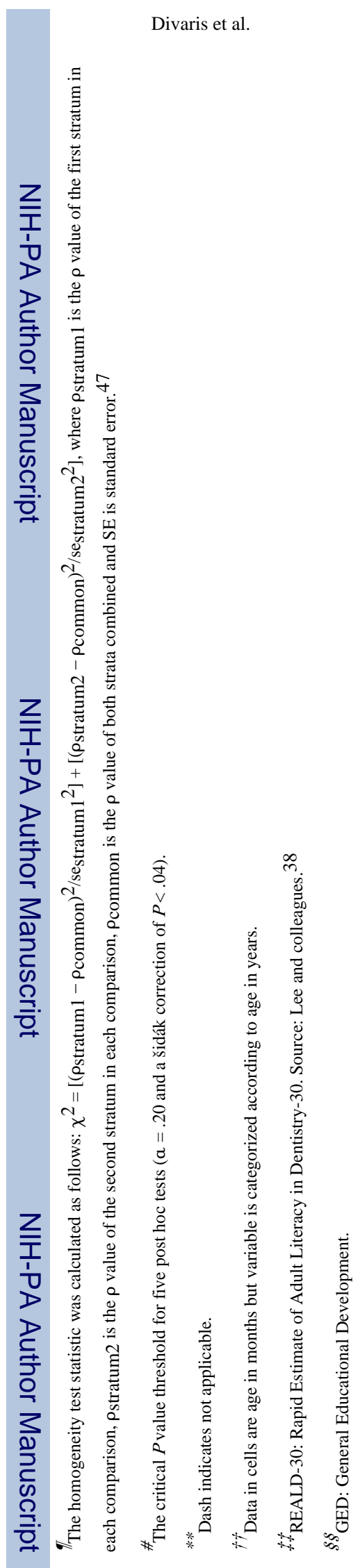

J Am Dent Assoc. Author manuscript; available in PMC 2013 November 01. 
TABLE 3

Caregivers' reports of children's oral health status and clinical assessments* in the Carolina Oral Health Literacy study. ${ }^{+}$

\begin{tabular}{|c|c|c|c|}
\hline \multirow{2}{*}{$\begin{array}{l}\text { CAREGIVER-REPORTED CHILD'S ORAL } \\
\text { HEALTH STATUS }\end{array}$} & \multicolumn{3}{|c|}{ NO. (\%) OF PARTICIPANTS } \\
\hline & No Treatment Needs & $\begin{array}{l}\text { Low to Moderate } \\
\text { Treatment Needs }\end{array}$ & Advanced Treatment Needs \\
\hline \multicolumn{4}{|l|}{ Total Sample $(\mathrm{N}=108)$} \\
\hline Excellent & $18(33)$ & $6(32)$ & $3(11)$ \\
\hline Very good & $14(26)$ & $5(26)$ & $2(7)$ \\
\hline Good & $18(33)$ & $7(37)$ & $4(14)$ \\
\hline Fair & $4(7)$ & $0(0)$ & $12(43)$ \\
\hline Poor & $0(0)$ & $1(5)$ & $7(25)$ \\
\hline \multicolumn{4}{|l|}{2 Years or Older } \\
\hline Excellent & $6(35)$ & $4(29)$ & $0(0)$ \\
\hline Very good & $6(35)$ & $3(21)$ & $0(0)$ \\
\hline Good & $4(24)$ & $6(43)$ & $3(23)$ \\
\hline Fair & $1(6)$ & $0(0)$ & $7(54)$ \\
\hline Poor & $0(0)$ & $1(7)$ & $3(23)$ \\
\hline \multicolumn{4}{|l|}{ Younger Than 2 Years } \\
\hline Excellent & $12(32)$ & $2(40)$ & $3(20)$ \\
\hline Very good & $8(22)$ & $2(40)$ & $2(13)$ \\
\hline Good & $14(38)$ & $1(20)$ & $1(7)$ \\
\hline Fair & $3(8)$ & $0(0)$ & $5(33)$ \\
\hline Poor & $0(0)$ & $0(0)$ & $4(27)$ \\
\hline \multicolumn{4}{|l|}{ University Clinic } \\
\hline Excellent & $6(23)$ & $0(0)$ & $0(0)$ \\
\hline Very good & $6(23)$ & $0(0)$ & $0(0)$ \\
\hline Good & $12(46)$ & $2(67)$ & $3(16)$ \\
\hline Fair & $2(8)$ & $0(0)$ & $11(58)$ \\
\hline Poor & $0(0)$ & $1(33)$ & $5(26)$ \\
\hline \multicolumn{4}{|l|}{ Community Clinic } \\
\hline Excellent & $12(43)$ & $6(38)$ & $3(33)$ \\
\hline Very good & $8(29)$ & $5(31)$ & $2(22)$ \\
\hline Good & $6(21)$ & $5(31)$ & $1(11)$ \\
\hline Fair & $2(7)$ & $0(0)$ & $1(11)$ \\
\hline Poor & $0(0)$ & $0(0)$ & $2(22)$ \\
\hline
\end{tabular}

Based on a modification of the caries severity index. Sources: Miller and colleagues, ${ }^{35}$ Poulson and Horowitz ${ }^{36}$ and Wong and colleagues. ${ }^{37}$

${ }^{\dagger}$ Source: Lee and colleagues. 33 
Numbers may not total 108 because of missing information in some strata. 